\title{
INVESTIGATIONS OF HYDRODYNAMIC CLEARING OF LIQUIDS BY THE PROPOSED PROFESSOR FINKELSTEIN Z.L.
}

\author{
Zhuraev A.Sh. ${ }^{1}$, Juraev R.U. ${ }^{2}$, Toirov M.Sh. ${ }^{3}$, Usmonov M.Z. ${ }^{4}$, Khamraev I.S. ${ }^{5}$, \\ Jumahulov M.Yu.6 (Republic of Uzbekistan) Email: Zhuraev341@ scientifictext.ru
}

\author{
${ }^{1}$ Zhuraev Akbar Shavkatovich - Assistant; \\ ${ }^{2}$ Juraev Rustam Umarhanovich - Associate Professor, \\ DEPARTMENT OF MINING ELECTROMECHANICS \\ ${ }^{3}$ Toirov Murtoz Shavkiddinovich - Senior Lecturer, \\ DEPARTMENT OF ENGINEERING TECHNOLOGY; \\ ${ }^{4}$ Usmonov Maftunzhon Zohidzhon ugli - Student; \\ ${ }^{5}$ Khamraev Islom Salim ugli-Student; \\ ${ }^{6}$ Jumahulov Mirzabek Yunusovich - Student, \\ DEPARTMENT OF MINING ELECTROMECHANICS, \\ NAVOI STATE MINING INSTITUTE, \\ NAVOI, REPUBLIC OF UZBEKISTAN
}

\begin{abstract}
The high degree of environmental contamination, the lack of reliable methods for sealing containers for working fluids and at the same time high requirements for the cleanliness of working fluids, especially at high operating pressures in systems, required the search for fundamentally new ways of cleaning working fluids from mechanical impurities. The result of the work is a number of significant solutions to improve the system of cleaning.
\end{abstract}

Keywords: working liquid, cleaning, fine filter, filter element.

\section{ИССЛЕДОВАНИЯ ГИДРОДИНАМИЧЕСКОЙ ОЧИСТКИ ЖИДКОСТЕЙ, ПРЕДЛОЖЕННОЙ ПРОФЕССОРОМ ФИНКЕЛЬШТЕЙНОМ З.Л. \\ Жураев А.Ш. ${ }^{1}$, Джураев Р.У. ${ }^{2}$, Тоиров М.Ш. ${ }^{3}$, Усмонов М.3. ${ }^{4}$, Хамраев И.С. ${ }^{5}$, Жумакулов М.Ю. ${ }^{6}$ (Республика Узбекистан)}

\author{
'Жураев Акбар Шавкатович - ассистент; \\ ${ }^{2}$ Джураев Рустам Умарханович - доиент, \\ кафедра горной электромеханики; \\ ${ }^{3}$ Тоиров Муртоза Шавкиддинович - старший преподаватель, \\ кафедра технологии матиностроения; \\ ${ }^{4}$ Усмонов Мафтунжон Зохиджон угли - студент; \\ ${ }^{5}$ Хамраев Ислом Салим угли - студент; \\ бЖумакулов Мирзабек Юнусович - студент, \\ кафедра горной электромеханики, \\ Навоийский государственный горный институт, \\ г. Навои, Республика Узбекистан
}

\begin{abstract}
Аннотация: авторы рассматривают важность и необходимость повышения очистки рабочей жидкости. Высокая степень загрязнённости окружающей среды, отсутствие надежных способов герметизации емкостей для рабочих жидкостей и в то же время высокие требования к чистоте рабочих жидкостей, особенно при высоких рабочих давлениях в системах, потребовали поиска принципиально новых путей очистки рабочих жидкостей от механических примесей. Итогом работь является ряд существенных решений усовершенствования системы очистки.
\end{abstract}

Ключевые слова: рабочей жидкости, очистка, фильтры тонкой очистки, фильтроэлемент.

Проблема достижения высокой степени очистки жидкостей принципиально решена промышленностью постсоветских стран, в том числе Узбекистане. В настоящее время выпускаются механические фильтры тонкой очистки, позволяющие достичь тонкости фильтрации в 5,2 и даже 0,5 мкм. Аналогично зарубежные фирмы “Отамотив продактс", “Бритиш фильтерс" (Великобритания) выпускают фильтрующие элементы (бумажные, войлочные и сетчатые) с тонкостью фильтрования 2,5, 10 и 25 мкм. Для очистки масла в переносных агрегатах фирма “Филтерпак” (Великобритания) выпускает фильтры тонкостью очистки 0,5-10 мкм.

По данным ВВС Великобритании, где чистоте рабочих жидкостей уделяется большое внимание, $80 \%$ всего времени жидкость поступает в систему через байпасные клапаны фильтра [1]. 
Суть предложенной проф. Финкельштейном 3.Л. гидродинамической очистки заключается в создании относительного движения фильтрующей поверхности и частицы в направлении, перпендикулярном направлению потока жидкости через ячейки в фильтрующем элементе (рис. 1) [2].

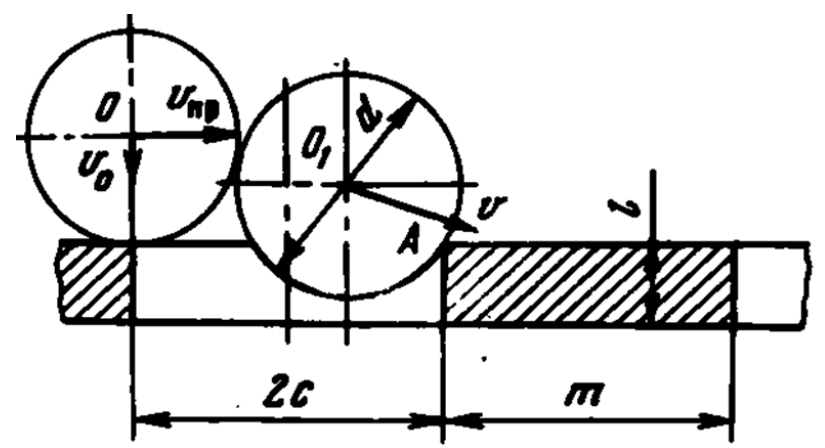

Рис. 1. Схема гидродинамической очистки

При определенных соотношениях величины поперечной и продольной составляющих относительной скорости частицы и фильтрующей поверхности достигается очистка жидкости от частиц механических примесей значительно меньших, чем размеры ячеек в свету. Исключается засорение этих ячеек крупными частицами, а, следовательно, обеспечиваются меньший перепад давлений на фильтрующем элементе, неизменность параметров при очистке в эксплуатации и непрерывная самогенерация. Схематично, все конструктивные варианты реализации гидродинамической очистки можно представить в виде фильтра с неподвижным фильтроэлементом, с вращающимся фильтоэлементом и с колеблющимся фильтроэлементом.

В первом случае (рис.2) разделение частиц по крупности перед ячейками осуществляется за счет потока вдоль фильтроэлемента, что требует сброса части жидкости из системы (неполнопоточные фильтры). Загрязненная жидкость расходом Q поступает через отверстие А; часть жидкости $\mathrm{Q}_{1}$ проходит через фильтроэлементы $\mathrm{B}$, очищается и через отверстие С поступает в гидравлическую систему, остаток жидкости $\mathrm{Q}_{2}$ сливается через отверстие D и через регулируемый дроссель Е, позволяющий изменить соотношение между очищенным потоком, и потоком обогащенным крупными частицами из загрязненной жидкости, и сбрасываемым через дроссельное отверстие в емкость.

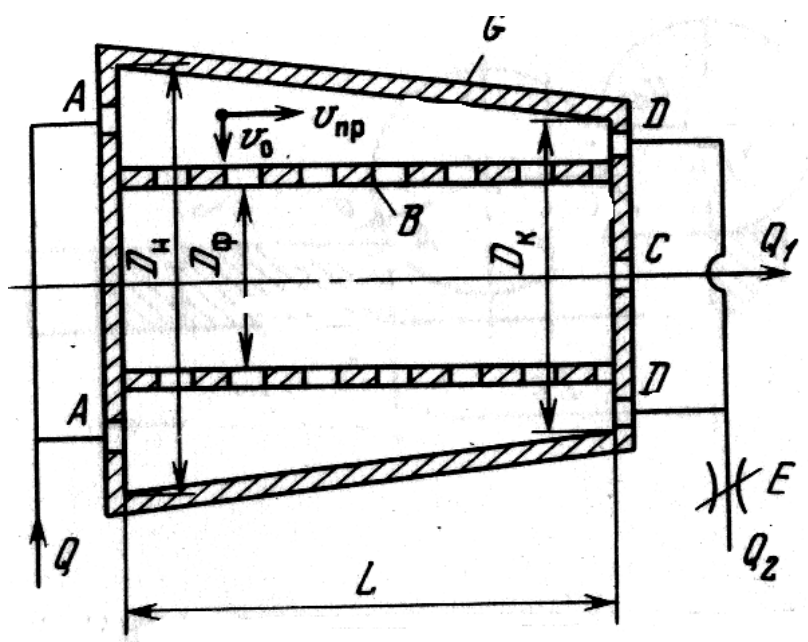

Рис. 2. Схема фильтра гидродинамического с неподвижным фильтроэлементом

Продольная скорость поддерживается постоянной за счет уменьшения зазора между корпусом $\mathrm{G}$ и фильтроэлементом В по длине L.

Указанные выше принципиальные схемы имеют свои преимущества и области применения.

Таким образом, тема исследования, направленная на создание очистителей жидкости, является актуальной как с точки зрения потребности в развитии теории рабочего процесса очистителей, так и с учетом практических задач, стоящих перед промышленностью сегодня.

\section{Список литературы / References}

1. Conference DIL Contamination in fluid power system Bath. 1976. London - New York, 1977. P. 144. 
2. Финкельштейн 3.Л. Гидродинамическая очистка жидкостей. / 3.Л. Финкельштейн, Л.Н. Бойко, Н.3. Бойко // Тр. НИИ прикладных проблем гидроаэромеханики и теплообмена. Черкассы. Изд. ЧИТИ, 1997. С. 29-35. 